\title{
DARK PERSONALITY AND ROAD CRASHES: MEDIATING ROLE OF DRIVER VENGEANCE AND VIOLATIONS
}

\author{
Nebi Sümer ${ }^{1}$, Bahar Tümer², Uluğhan Ergin², Seda Merve Şahin ${ }^{3}$ \\ ${ }^{1}$ Sabanc1 University \\ İstanbul, Turkey \\ ${ }^{2}$ Middle East Technical University \\ Ankara, Turkey \\ Email: nebisumer@sabanciuniv.edu
}

\begin{abstract}
Summary: Aggressive driving and road rage are increasingly leading to Motor Vehicle Collisions (MVC), especially in the developing countries. Considering that malevolent personality characteristics, such as dark triad (narcissism, Machiavellianism, and psychopathy) create a tendency for vengeful and aggressive driving, we examined the power of personality variables in predicting MVC. Specifically, using Contextual Mediated Model (Sümer, 2003), we tested a double mediation model in which driving anger and vengeance mediate the relationships between personality characteristics (Big Five Traits and Dark Triad) and driving violations, and in turn, driving violations mediate the link between driving anger/vengeance and risky driving outcomes (MVC and traffic tickets). Turkish drivers $(\mathrm{N}=485$, female $=\% 51)$ completed the measures of personality, aberrant driving behaviors, vengeance, and driving anger. Results of path analyses revealed that whereas narcissism and neuroticism are the critical predictors for aggressive driving Machiavellianism is the strongest predictor of driving vengeance. Moreover, Machiavellianism both directly and indirectly via driving vengeance and violations predicted MVC. Personality variables and mediating variables explained $21 \%$ and $26 \%$ of the variance in MVC and traffic tickets, respectively, values much higher than those previously reported in the past research. Findings have critical implications for the assessment of aggressive drivers and potential for road rage.
\end{abstract}

\section{INTRODUCTION}

Aggressive driving (i.e., violations of traffic laws with a harmful intension directed toward other motorists, especially via excessive speeding, tailgating, and reckless driving) and road rage (i.e., extreme acts of driving aggression involving personal assault or direct violence) have become an increasingly worldwide public epidemic and serious risk factors for road users. According to AAA Foundation for Traffic Safety (2009), fatal motor vehicle collusions (MVC) caused by aggressive driving have increased 56\% between 2003 and 2007 in the US. Moreover, MVC associated with road rage has increased about 500\% from 2006 to 2015 (Johnston, 2018). The incidence of aggressive driving differ across the world regions and it is relative higher in Turkey than some other European countries (Özkan et al., 2011). Considering its critical role in MVC, traffic safety researchers have recently begun to focus more on driving aggression and road rage rather than driving violations (see Wickens et al., 2013).

Past studies have documented that certain personality characteristics such as Big Five traits (e.g., Sümer et al 2005) and narcissism (e.g., Bushman et al., 2018) are associated with risky driving 
behaviors as well as MVC and the other traffic causalities. However, the mechanisms by which certain personality traits are associated with aggressive and risky driving and the resulting MVC need further investigation. Previous research has demonstrated that drivers with certain personality characteristics, such as narcissism or Machiavellianism, have more negative emotionality, and thus, make more intention attributions to other drivers' behaviors resulting in more retaliatory and vengeful behavior on the road (see Lustman et al., 2010; Wickens et al., 2013). Especially, vengeance behavior, which is defined as intending to harm the other party as a consequence of perceived injustice, is closely linked with hostile attributions to other drivers' intentions (see Wickens, et al , 2015). Although past studies have documented the role of personality traits, especially the Big Five Traits on risky driving (e.g., Sümer et al., 2005), their effect on driving vengeance and MVC needs further exploration. Furthermore, we still do not know the direct and indirect effects of the malevolent personality traits, namely the dark triad of narcissism, Machiavellianism, and psychopathy, on driving vengeance, aggression, and violations as well as resulting MVC.

People with dark personality characteristics can especially be risky in the driving environment because they commonly tend to perceive the other driver behaviors as threatening and show retaliatory responses. Machiavellianism refers to a strategic understanding towards manipulating environment and other people according to person's best interest, whereas narcissism refers to exaggerated high opinions towards oneself that might lead to aberrant behavior towards others. Psychopathy is an antisocial trait that is characterized by impulsivity in behavior and lack of affect (Jones \& Paulhus, 2014). Drivers with these negative personality traits intend to harm the other road users as a consequence of perceived threat and injustice (Wickens, Wiesenthal, \& Roseborough, 2015). They are especially prone to anger driven emotional states and vengeful behaviors, such as honking, swearing, yelling or even deliberately crashing into other motorist's vehicle, especially when the traffic environment is ambiguous and the social/cultural norms for obeying the rules are not strong enough (Wiesenthal, Hennessy, \& Gibson 2000).

Driving anger as an emotional state is almost always accompanied by vengeful behaviors and it has been found to be associated with various driving outcomes from aggressive driving to driving errors (see Demir, Demir, \& Özkan, 2016). Furthermore, it appears to have a unique role in transferring the negative effect of certain personality characteristics to aggressive and risky driving. This study aims to examine the role of driving anger and vengeance in mediating the relationships between personality dimensions (both the Big Five Traits and Dark Triad) and risky and aggressive driving outcomes (i.e., MVC and traffic tickets).

Specifically, we used Sümer's (2003) Contextual Mediated Model that distinguishes the effects of distal context (such as personality traits and driving environment) from the mediating proximal context (such as aberrant driver behaviors and impaired driving) in predicting MVC and proposed a double mediation model. In the first step, driving vengeance and anger are expected to mediate the effect of personality (Big Five traits and Dark Triad) on driving violations. In the second step, violations as the most proximal mediator variable is expected to mediate the effects of driving vengeance and anger on MVC and traffic tickets. We also included driver gender, age, and $\mathrm{km}$ driven per year as the distal predictors into our model considering their effects on risky driving and its outcomes. 


\section{METHOD}

\section{Participants}

Drivers $(\mathrm{N}=485$, females $=51 \%)$ who had an active driving experience at least for one year completed the following measures online using Qualtrics. Mean age of the participants was 25.73 years $(\mathrm{SS}=8.21), 37 \%$ had a university degree, and the remaining participants had high school degree or a lover level of education attainment. Average of annual kilometers driven was $14,310(\mathrm{SS}=10,71)$.

\section{Measures}

Participants first responded to demographic questions, km driven per year, number of MVC they had had in the last three years and traffic ticket taken in the last year. They then filled out the Turkish versions of the following scales.

Big Five Inventory -2 (BFI-2, Soto, \& John, 2017) was used to assess Extraversion, Agreeableness, Conscientiousness, Negative Emotionality, and Open-Mindedness. BFI-2 had 60 items and all of the five domains had good reliability coefficients (see Table 1).

Short Dark Triad (SD3): The 12 item measure adapted by Özsoy, Rauthmann, Jonason, and Ardıç (2017) was used to measure Machiavellianism, psychopathy, and narcissism.

Driver Anger Scale (DAS): Turkish version of 14-item DAS developed by Deffenbacher, et al., (1994) was used to measure driving anger (Yasak \& Esiyok, 2009).

Driver Behavior Questionnaire (DBQ): The 13-item violation subscale of the DBQ was used to assess self-reported driving violations (Sümer \& Özkan, 2002).

Driver Vengeance Questionnaire (DVQ): The DVQ assesses drivers' vengeful feelings when faced with different driving situations (Wiesenthal et al., 2000). The DVQ consists of 15 scenarios and asks drivers to indicate how they would respond in a given situation. The DVQ was adapted to Turkish in this study.

\section{RESULTS AND DISCUSSION}

Of the participants, $38 \%$ reported having no MVC, $27 \%$ reported one accident only, and $34 \%$ reported two or more MVC in the last three years. Total number of traffic violation tickets taken in the last years ranged from 0 to 10 . Descriptive statistics and correlations among the major variables in the study were presented in Table 1 . As expected, male drivers had significantly higher levels of driving vengeance, aggressive violations, and neuroticism than did female drivers. Age of drivers and $\mathrm{km}$ driven per year were significantly correlated with many variables in the expected directions, and thus were included in the model as control variables. The number of MVC was significantly correlated with violations and traffic tickets only. Correlations between the personality traits and presumed mediators showed that agreeableness and conscientiousness were negatively and Machiavellianism was positively and moderately strongly associated with vengeful and aggressive behaviors on the road. 
We tested the proposed double mediation model using path analyses (structural equation modeling) via LISREL. We first estimated the full-saturated model with all of the direct and indirect paths between independent variables (i.e., personality variables, gender, age and $\mathrm{km}$ driven) and mediators (i.e., driver anger and vengeance), and outcome variables (i.e., MVC in last three year and traffic tickets in the last year). Following the examination of the path coefficients in the model, we re-run the analyses by trimming the insignificant paths. We also added a correlated error between MVC and traffic tickets, which had high covariance.

The final model presented in Figure 1 yielded a very good fit to data $\left(\mathrm{x}^{2}(34) ; \mathrm{N}=485=37.99, \mathrm{p}\right.$ $=.29 ; \mathrm{GFI}=.99, \mathrm{AGFI}=.97$, RMSEA $=.02$ ). Of the Big Five traits, openness did not have a significant effect on any of the variables. Extraversion had a weak but significant effect on violations.

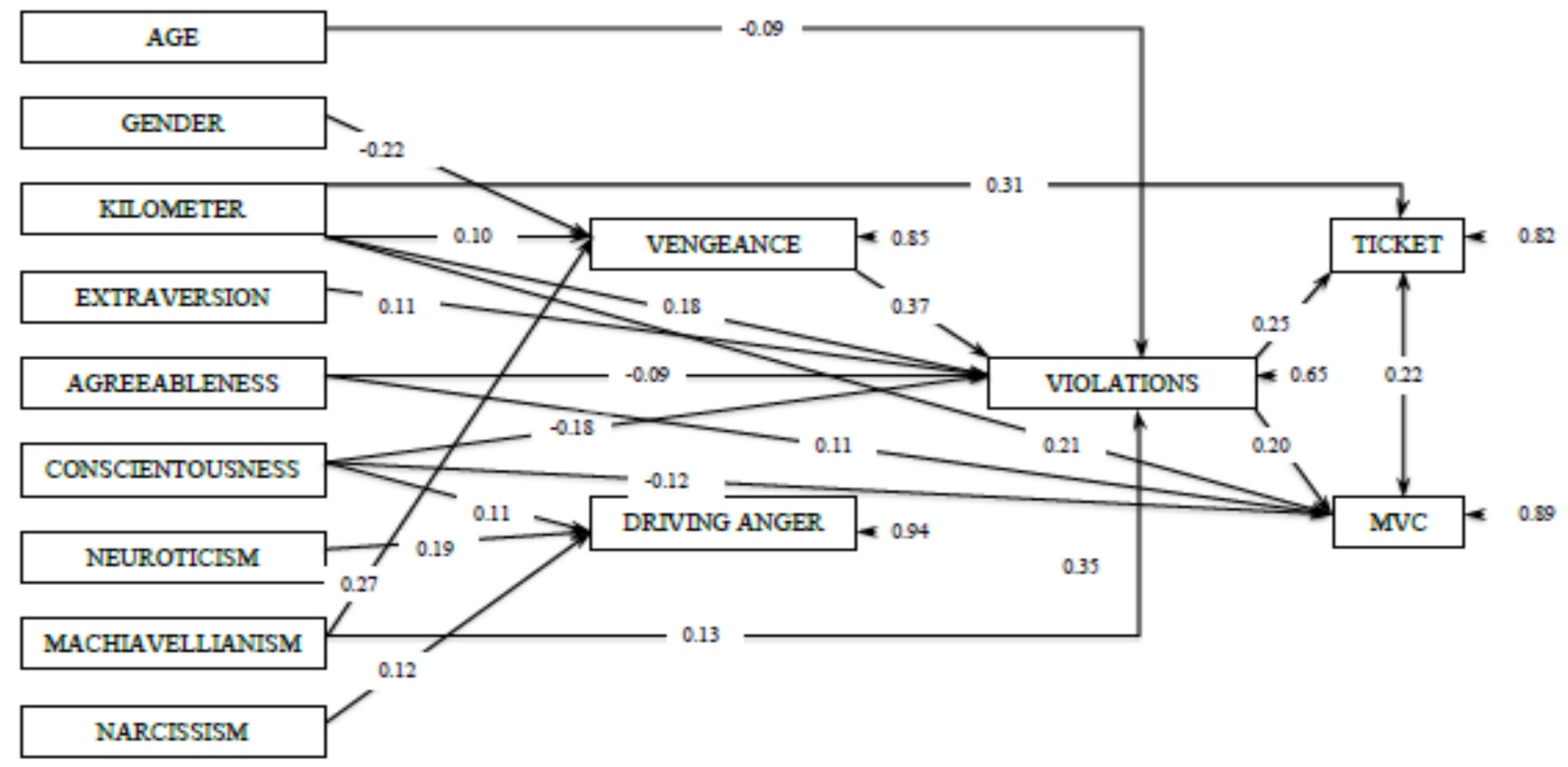

Figure 1: Path model of the effects of Big Five Traits and Dark Triad on MVC and Tickets, mediated by ageressive driving. 
PROCEEDINGS of the Tenth International Driving Symposium on Human Factors in Driver Assessment, Correlations, Means, Standard Deviations and Reliability Coefficients for the Major Trqining and Vehicle Design

\begin{tabular}{|c|c|c|c|c|c|c|c|c|c|c|c|c|c|c|c|c|}
\hline Measures & 1 & 2 & 3 & 4 & 5 & 6 & 7 & 8 & 9 & 10 & 11 & 12 & 13 & 14 & 15 & 16 \\
\hline \multicolumn{17}{|l|}{ 1. Age } \\
\hline 2. Gender & $-.10 *$ & & & & & & & & & & & & & & & \\
\hline $\begin{array}{l}\text { 3. KM per year } \\
\text { (thousand) }\end{array}$ & $.18 * *$ & $-.18 * *$ & & & & & & & & & & & & & & \\
\hline 4. MVC & -.08 & $-.11 *$ & $.24 * *$ & & & & & & & & & & & & & \\
\hline 5. Driving Tickets & .00 & $-.17 * *$ & $.35 * *$ & $.37 * *$ & & & & & & & & & & & & \\
\hline 6. Extraversion & .05 & .014 & $.12 *$ & -.02 & .01 & $(.85)$ & & & & & & & & & & \\
\hline 7. Agreeableness & $.15^{* *}$ & $.13^{* *}$ & .07 & .03 & .004 & $.13 * *$ & $(.80)$ & & & & & & & & & \\
\hline 8. Conscientiousness & $.21 * *$ & $.12 * *$ & $.10^{*}$ & $-.13 * *$ & -.01 & $.21 * *$ & $.31 * *$ & $(.87)$ & & & & & & & & \\
\hline 9. Neuroticism & $-.14 * *$ & $.11 * *$ & $-.10^{*}$ & -.01 & .004 & $-.29 * *$ & $-.37 * *$ & $-.31 * *$ & $(.85)$ & & & & & & & \\
\hline 10. Openness & $.12 * *$ & .09 & .21 & -.09 & .01 & $.30 * *$ & $.20 * *$ & $.18 * *$ & $-.12 * *$ & $(.83)$ & & & & & & \\
\hline 11. Driver Anger & -.04 & $.09 *$ & -.02 & -.01 & .02 & .05 & $-.10 *$ & .02 & $.21 * *$ & $-.09 *$ & $(.82)$ & & & & & \\
\hline 12. Machiavellianism & $-.16 * *$ & $-.12 * *$ & -.10 & .06 & .005 & .05 & $-.46^{* *}$ & $-.34 * *$ & $0.20 * *$ & $-.14 * *$ & $.11 *$ & $(.77)$ & & & & \\
\hline 13. Psychopathy & $-.10^{*}$ & $-.13 * *$ & -.07 & -.03 & .05 & .01 & $-.55 * *$ & $-.22 * *$ & .06 & $-.13 * *$ & .03 & $.50 * *$ & $(.61)$ & & & \\
\hline 14. Narcissism & $-.12 *$ & .01 & $\begin{array}{c}- \\
.12^{* *}\end{array}$ & .03 & .02 & $.01 *$ & $-.34 * *$ & $-.24 * *$ & $.24 * *$ & $-.12 * *$ & $.16^{* *}$ & $.49 * *$ & $.35 * *$ & $(.89)$ & & \\
\hline 15. Violation & $-.11 *$ & $-.23 * *$ & $.19 * *$ & $.24 * *$ & $.10 *$ & $.11^{*}$ & $-.26 * *$ & $-.27 * *$ & $.11^{*}$ & $-.12 * *$ & $.13 * *$ & $.35^{* *}$ & $.23 * *$ & $.22 * *$ & $(.83)$ & \\
\hline 16. Vengeance & .04 & $-.26 * *$ & $.12 *$ & $.01 *$ & $.01^{*}$ & .08 & $-.18 * *$ & $-.11 *$ & .09 & $-.11 *$ & $.24 * *$ & $.30 * *$ & $.18^{* *}$ & $.17 * *$ & $.47 * *$ & $(.74)$ \\
\hline Mean & 25.73 & .51 & 14.27 & 1.19 & 1.37 & 3.44 & 3.79 & 3.52 & 2.84 & 3.85 & 3.16 & 2.81 & 2.76 & 4.05 & 2.11 & 2.00 \\
\hline SD & 8.21 & .5 & 10.01 & 1.27 & 2.67 & .63 & 0.51 & 0.65 & 0.65 & 0.58 & 0.60 & 1.45 & 1.35 & 2.06 & 0.64 & 0.36 \\
\hline
\end{tabular}

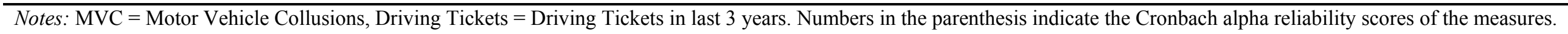
$* p<.05, * * p<.01$ 
Neuroticism had an effect on driving anger. Agreeableness had significant effects on violations and MVC, and conscientiousness had significant effects on driving anger, violations, and MVC. Of Dark Triads, narcissisms predicted driving anger and Machiavellianism predicted driving vengeance and violations.

Examination of the indirect (mediated) effects showed that driving vengeance mediated the link between Machiavellianism together with gender and violations, suggesting that being male and having higher levels of Machiavellianism indirectly predicted traffic violation via heightening driving vengeance. Driving anger, however, did not have a mediated effect. As expected, violations also significantly mediated the associations between driving vengeance and the two outcome variables, MVC and traffic tickets.

Specifically, partially supporting the proposed double mediation model, results demonstrated the indirect effects of personality variables, especially dark triad predicted accident risk via driving vengeance and violations. Machiavellianism and gender (being male) had significant effects on violations via driver vengeance (Indirect effects $=.10$ and .08 , respectively) signifying the chief role of vengeful anger in violations and resulting road crashes. Considering all of the direct and indirect effects, $21 \%$ of the variance in MVC and $26 \%$ of the variance in traffic tickets were explained by personality and the mediating variables, and $\% 30$ of the variance in traffic tickets were explained by personality and mediating variables.

Our findings have critical implications for detection and assessment of risky drivers as well as developing rehabilitation programs for aggressive drivers, designing effective traffic safety campaigns targeting to enhance awareness for safe driving, and protecting public against road rage.

\section{REFERENCES}

AAA Foundation for Traffic Safety (2009). 2009 Traffic Safety Culture Index. AAA Foundation for Traffic Safety.

Bushman, B. J., Steffgen, G., Kerwin, T., Whitlock, T., \& Weisenberger, J. M. (2018). "Don’t you know I own the road?" The link between narcissism and aggressive driving.

Transportation research part F: traffic psychology and behaviour, 52, 14-20.

Deffenbacher, J. L., Oetting, E. R., \& Lynch, R. S. (1994). Development of a driving anger scale. Psychological Reports, 74, 83 \pm 91

Demir, B., Demir, S., \& Özkan, T. (2016). A contextual model of driving anger: A metaanalysis. Transportation Research Part F: Traffic Psychology and Behaviour, 42, 332349.

Jones, D. N., \& Paulhus, D. L. (2014). Introducing the short dark triad (SD3) a brief measure of dark personality traits. Assessment, 21(1), 28-41.

Johnston, J. E. (2018). The road to rage: From aggressive driving to anger, arguments and assault. Psychology Today, March 30, 2018. Retrieved from https://www.psychologytoday.com/intl/blog/the-human-equation/201803/the-road-rage

Lustman, M., Wiesenthal, D. L., \& Flett, G. L. (2010). Narcissism and Aggressive Driving: Is an Inflated View of the Self a Road Hazard? Journal of Applied Social Psychology, 40(6), 1423-1449. 
Özkan, T., Lajunen, T., \& Summala, H. (2006). Driver Behaviour Questionnaire: A follow-up study. Accident Analysis \& Prevention, 38(2), 386-395.

Özkan, T., Lajunen, T., Parker, D., Sümer, N., \& Summala, H. (2011). Aggressive driving among British, Dutch, Finnish, and Turkish drivers. International Journal of Crashworthiness, 16, 233-238

Özsoy, E., Rauthmann, J. F., Jonason, P. K., \& Ardıç, K. (2017). Reliability and validity of the Turkish versions of Dark Triad Dirty Dozen (DTDD-T), Short Dark Triad (SD3-T), and Single Item Narcissism Scale (SINS-T). Personality and Individual Differences, 117, 1114.

Soto, C. J., \& John, O. P. (2017). The next Big Five Inventory (BFI-2): Developing and assessing a hierarchical model with 15 facets to enhance bandwidth, fidelity, and predictive power. Journal of Personality and Social Psychology, 113(1), 117.

Sümer, N. (2003). Personality and behavioral predictors of traffic accidents: testing a contextual mediated model. Accident Analysis \& Prevention, 35(6), 949-964.

Sümer, N., Lajunen, T., \& Özkan, T. (2005). Big five personality traits as the distal predictors of road accident. Traffic and transport psychology: Theory and application, 215. doi:10.1016/B978-008044379-9/50173-4

Sümer, N., \& Özkan. T. (2002). Sürücü Davranışları, Becerileri, Bazı Kişilik Özellikleri ve Psikolojik Belirtilerin Trafik Kazalarındaki Rolleri. Türk Psikoloji Dergisi, 50, 1-26.

Yasak, Y., \& Esiyok, B. (2009). Anger amongst Turkish drivers: Driving Anger Scale and its adapted, long and short version. Safety Science, 47(1), 138-144.

Wiesenthal, D. L., Hennessy, D., \& Gibson, P. M. (2000). The Driving Vengeance Questionnaire (DVQ): The development of a scale to measure deviant drivers' attitudes. Violence and Victims, 15(2), 115.

Wickens, C. M., Roseborough, J. E., Hall, A., \& Wiesenthal, D. L. (2013). Anger-provoking events in driving diaries: A content analysis. Transportation research part F: traffic psychology and behaviour, 19, 108-120.

Wickens, C. M., Mann, R. E., \& Wiesenthal, D. L. (2013). Addressing driver aggression: Contributions from psychological science. Current Directions in Psychological Science, 22(5), 386-391.

Wickens, C. M., Wiesenthal, D. L., \& Roseborough, J. E. (2015). Personality Predictors of Driver Vengeance. Violence and Victims, 30(1), 148-162. 